\title{
Verification of Use of the Critical View of Safety Technique during Laparoscopic Cholecystectomy in a Rural Hospital: A Retrospectivse Study
}

\author{
AHMED E. MORAD, M.D.; HOSSAM A. ABO EL AZM, M.D. and \\ MOHAMMED ABD EL WAHED ABDO, M.Sc.
}

The Department of General Surgery, Faculty of Medicine, Ain Shams University

\begin{abstract}
Background: Cholelithiasis is the most popular biliary illness and one of the extremely common causes of abdominal pain as it is present in $10-15 \%$ of the overall individuals. Though it is asymptomatic in most of them (>80\%); virtually, $1-2 \%$ of asymptomatic patients will develop symptoms necessitating cholecystectomy annually; making cholecystectomy the furthermost common operation performed by general surgeons.
\end{abstract}

Aim of Study: This study aimed in this study to verify the use of the critical view of safety during laparoscopic cholecystectomy in a rural hospital regarding the efficacy of the technique, difficulties during of the technique and baiout techniques, operative time and postoperative outcome at early learning curve for safe cholecystectomy.

Patients and Methods: A retrospective study conducted in Kafr El sheikh General Hospital during the period from 1 January 2019 to 1 January 2020. This study included 500 patients who presented with symptomatic cholelithiasis who had underwent laparoscopic cholecystectomy under general anesthesia using Critical View of Safety (CVS) as standardized technique and bailout tecniques in difiicult cases.

Results: There were $20(4 \%)$ of cases were found to have been falling in the age group (20-30) years, $200(40 \%)$ of them were falling in the age group (31-40), 220 (44\%) had an age ranged between (41-50) years, whereas $60(12 \%)$ of patients were in the age group 51-60 years, The mean age was $41.82 \pm 7.65$ years. In this study, 170 males $(34 \%)$ and 330 female $(66 \%)$ were recruited, with the mean body mass index was 29.8 , acheivement of CVS was (84\%), conversion to open as bailout technique were $40(8 \%)$, subtotal cholecystectomy as abailout technique were 30 cases $(6 \%)$, fundus first technique as abailout technique were 7 cases (1.4\%), tube cholecystostomy as abailout technique were 3 cases $(0.6 \%)$.

Conclusion: This study concluded that Critical View of Safety is the safest technique for recognizing the biliary anatomy during laparoscopic cholecystectomy and it is associated with a significant impact in preventing intraoperative complications and post operative major complication.

Correspondence to: Dr. Mohammed Abd El Wahed Abdo, E-Mail: mohamed.salem200385@gmail.com
Key Words: Safety technique - Laparoscopic cholecystectomy.

\section{Introduction}

CHOLELITHIASIS is the most popular biliary illness and one of the extremely common causes of abdominal pain as it is present in $10-15 \%$ of the overall individuals. Though it is asymptomatic in most of them (>80\%); virtually, $1-2 \%$ of asymptomatic patients will develop symptoms necessitating cholecystectomy annually; making cholecystectomy the furthermost common operation performed by general surgeons $[\mathbf{1 , 2}]$.

The advantages of laparoscopic cholecystectomy in the early 1990 s led to a paradigm change and shift from open approach towards minimally invasive techniques, better visualization, lower post-operative pain, shorter hospital stay and proper cosmosis $[3,4]$.

The incidence of biliary injuries after conventional open cholecystectomy is about $0.2 \%$ [6].

On the other hand, despite of the advantages and improvements in techniques of laparoscopic cholecystectomy, the complication rates of intraoperative bile duct injuries still present and account for about $0.4 \%$ to $0.5 \%$ depending on the underlying disease [7].

Factors affecting the outcomes of LC have been heavily investigated over the past years. There are various pre or intraoperative factors that make LC a technically difficult procedure. These include acute cholecystitis, empyema gall bladder, gangrenous cholecystitis, fibrosed gallbladder, severe adhesions in calot's triangle and intrahepatic gall bladder. These problems are difficult to assess preoperatively but are usually encountered during 
LC and therefore responsible for major difficulty in performing the surgery [8]

The most common cause of intra-operative biliary injury is mis-identification, Strasberg and colleagues in 1995 suggested a strategy called the "critical view of safety" (CVS), to minimize the risk of bile duct injuries during laparoscopic cholecystectomy [9].

The CVS has 3 principles: First, the triangle of Calot must be cleared of fat and fibrous tissue. It does not require that the common bile duct be exposed. The second, requirement is that the lowest part of the gallbladder be separated from the cystic plate, the flat fibrous surface to which the nonperitonealized side of the gallbladder is attached. The cystic plate, which is sometimes referred to as the liver bed of the gallbladder. The third, requirement is that only 2 structures (cystic duct, cystic artery), should be seen entering the gallbladder. Once these 3 criteria have been fulfilled, CVS has been attained [10].

Strict adherence to this (CVS) during laparoscopic cholecystectomies throughout the procedure markedly reduce the incidence of bile duct injuries during this minimally invasive procedure [11]

The use of critical view of safety technique during laparoscopic cholecystectomies prevents transection of the common bile duct through critical examination of the present anatomy. Also, this technique offers an intraoperative full protection to the biliary tract when consistently implemented [3].

It was reported that to minimize biliary injuries, the (CVS) should be obtained in every patient during laparoscopic cholecystectomy, regardless of difficulty during dissection of Calot's triangle. As it is a safe, effective and easily applied method even by junior surgeons with limited laparoscopic experience, so should be established as the standard in training for laparoscopic cholecystectomy [12]

\section{Aim of the work:}

The aim of this work is to verify the use of the critical view of safety during laparoscopic cholecystectomy in a rural hospital regarding difficulties during the technique, operative time and postoperative outcome at the early learning curve.

\section{Patients and Methods}

Study design:

A retrospective study.
Study setting:

This study conducted in Kafr El Sheikh General Hospital during the period from 1 January 2019 to 1 January 2020.

\section{Study population:}

Inclusion criteria:

All patients who presented with symptomatic cholelithiasis who had underwent laparoscopic cholecystectomy which defied as any cholecystectomy started laparoscopically even if it converted to open procedure. /old.

Sampling method: Randomized age $12-60$ years

\section{Ethical considerations:}

Obtaining approval from The Institutional Research Board, oral and written informed consents from all participants, obtain informed consent was done discuss conversion to open cholecystectomy (4-5) \%, the risk of bleeding, infection, bile leak and bile duct injury.

\section{Methods:}

The files of the patients were studied regarding pre operative data, operative data sheet, post operative data and discharge sheet. The patient's history, results of pre operative examinations, any diagnostic procedures was analyzed searching for risk factors. Any operative difficulties reported were analyzed including type, time of diagnosis and their fate. Finally, any complications encountered were studied including type, diagnosis, management and fate.

\section{A- Full history taking:}

With considerable emphasis on: Symptoms of biliary colic (Number of attacks), history of acute cholecystitis (colic, fever, nausea, vomiting, hospital admission...), history of jaundice, history of cholangitis (fever, rigors, jaundice...), history of pancreatitis (fever, upper abdominal pain which radiates to the back and decreased by leaning forwards, nausea, jaundice...), previous abdominal operations, any medication intake, any comorbidity as I.H.D, Athamic ptns, COPD.

\section{$B$ - Full clinical examination:}

- General examination: Vital signs and general condition of the patient.

- Anthropometric measurements.

- Abdominal examination: With special emphasis on: Maximum point of tenderness, rebound tenderness, guarding at Rt hypochondrium (Murphy's Sign), Inspiratory arrest with deep palpation in the right upper quadrant. 
- Special signs: (Boas' sign), an area of hyperaethesia may be elicted between the 9 th to the $11^{\text {th }}$ ribs posteriorly on the right side.

\section{C-Investigations for preoperative assessment:}

CBC, PT, PTT, INR, Creatinine, Urea, $\mathrm{Na}^{+}, \mathrm{k}+$, Bilirubin (total, direct), SGOT, SGPT, albumin, HBSAg, HCV Ab, HIV Ab, ECG > 35 years old, Echocardiography $>50$ years or HTN patient, Amylase, lipase in gall stone pancreatitis, Alkalinephosphatase, GGT (Gamma-glutamyl transferase).

\section{$D$ - Imaging:}

- Abdominal U/S examination for: Detection Number of stones of GB, Content of GB and GB polyp.

- Magnetic Resonance Cholangio Pancreaticography (MRCP) done in history, post operative in biliary leakage and jaundice.

- Endoscopic Retrograde Cholangio Pancreaticography $(\mathrm{ERCP})$ in history of patient and post operative.

\section{Technique:}

All patients enrolled in the study were operated approximately the same the standard laparoscopy procedure was done Figs. (1-5). Pre-operative 1.2 amoxycillin clavulanic acid single intravenous dose half an hour before procedure.

\section{Positioning and theatre set-up:}

Patient is supine position Fig. (1): Consider using table gel mat and strapping to prevent patient sliding. Patient's arms were kept tucked beside body on arm boards, surgeon and scrub stand on patient's left, monitor on patient's right near head end, scrub nurse on patients right at foot end in north American position, foley catheter, nasogastric tube, and knee-high pneumatic Apparatus in highrisk case.

Evaluation of intraoperative risk factors of laparoscopic cholecystectomy:

Patients were evaluated for the following intraoperative risk factors from operative sheet and images taken during the procedure including intraoperative image of adhesions of gallbladder, ability to hold gallbladder, presence of pus/bile outside the gallbladder, distended gall bladder, size of impacted stone, gallbladder wall thickness and gallstones, intra-abdominal adhesions obscuring the access, cholecystitis with impending rupture with pus Figs. $(6,7)$.

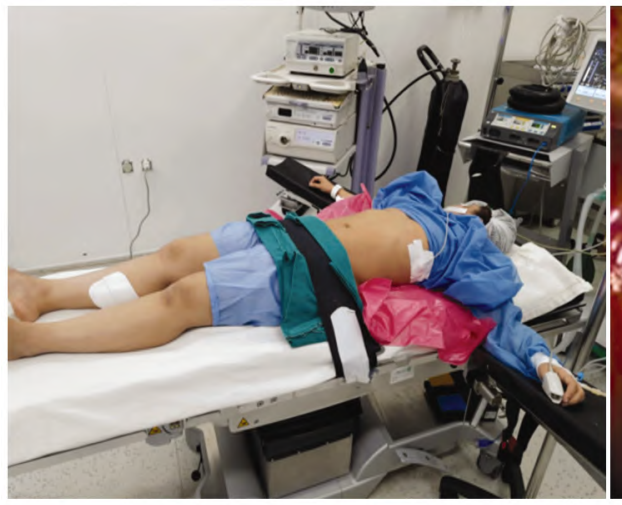

Fig. (1): Supine position of laproscopic cholecystectomy.

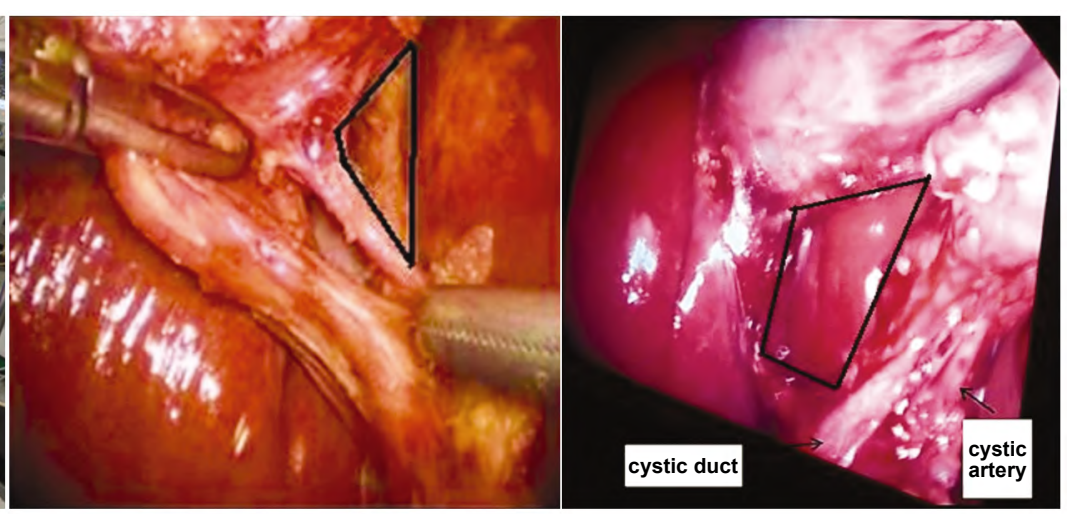

Fig. (2): Critical view of safety (ant. view), Fig. (3): Critical view of safety lower third of the cystic plate. (post. view).

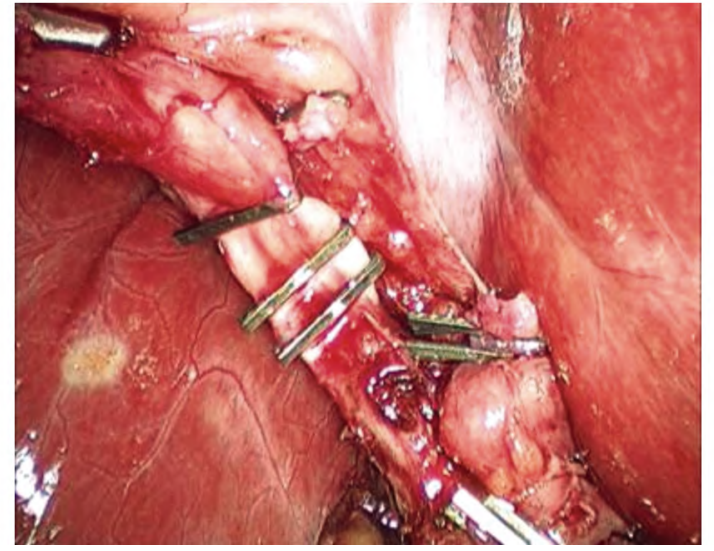

Fig. (4): Endoclips on both cystic artery and cystic duct.

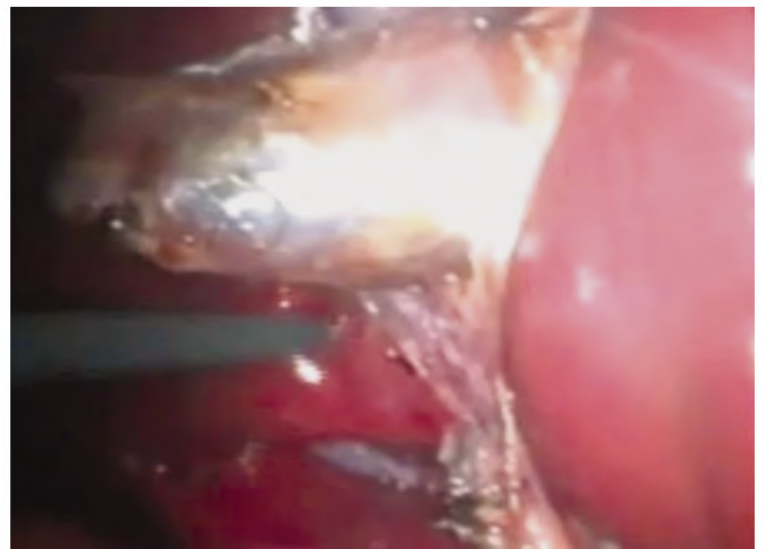

Fig. (5): Dissection of the GB from the liver bed. 

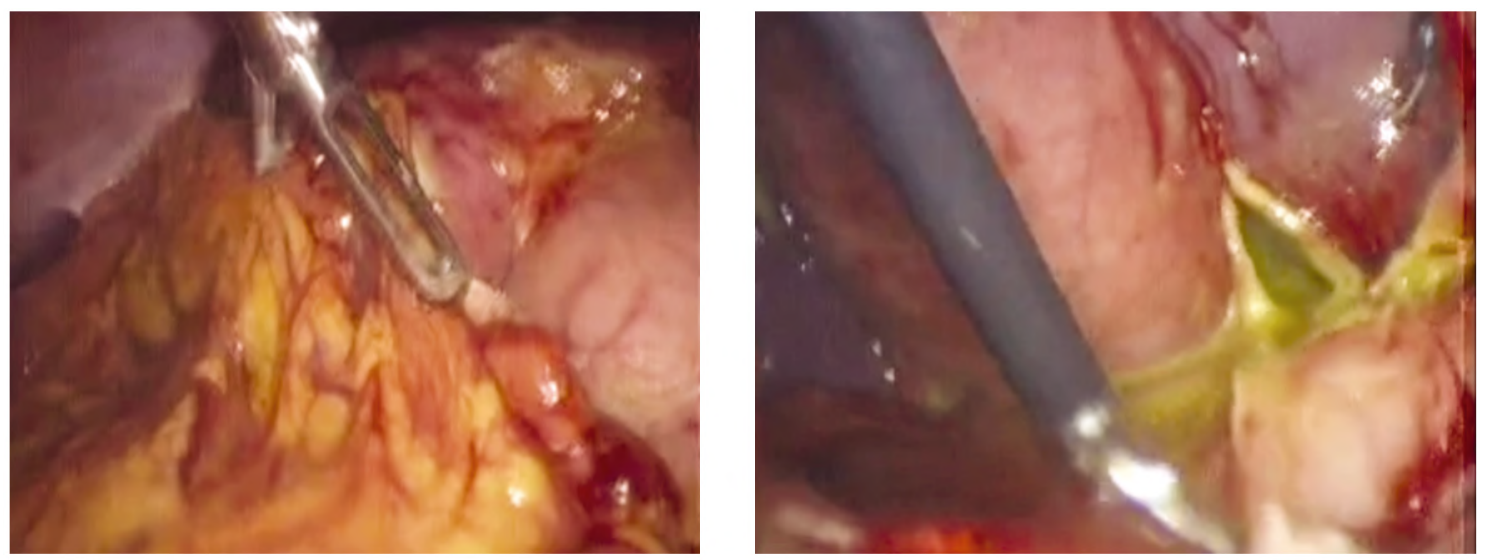

Fig. (6): A case with adhesions, distended and pus in gall bladder.
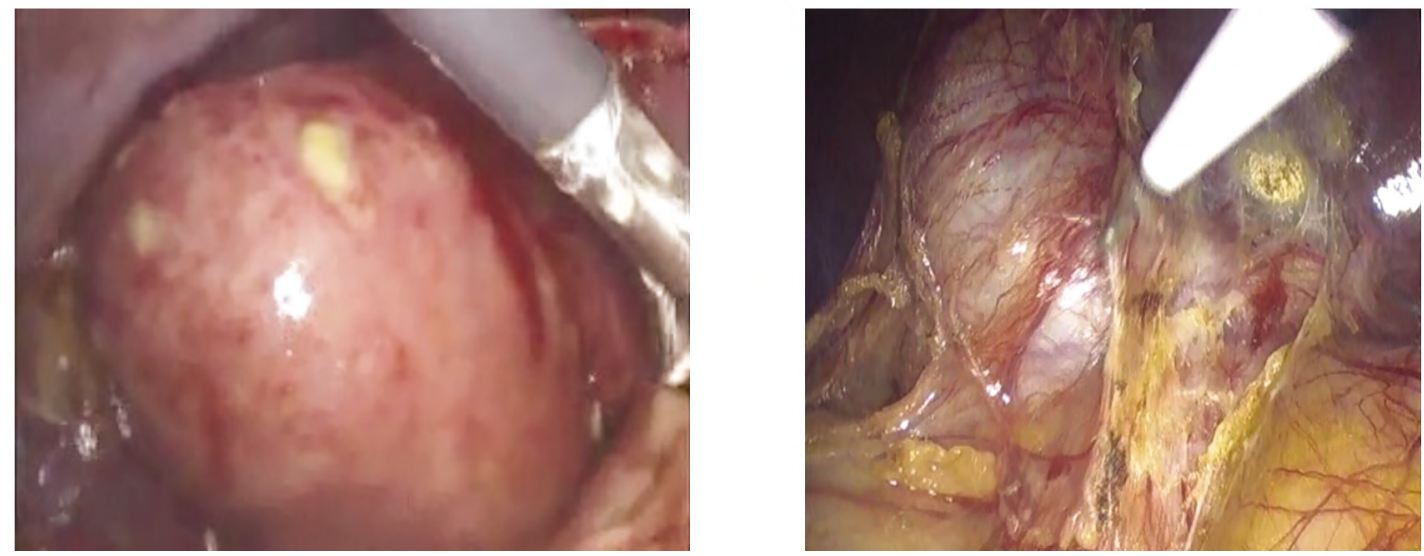

Fig. (7): Acute cholecystitis and distented gall bladder.

\section{E- Postoperative work up:}

Fast track surgery enhance recovery, patient controlled anathesia, recovery of bowel sound, monitoring the drain output, hospital stays, postoperative outcome (complications, readmissions, morbidity and mortality), post-operative visit follow-up for any recurrent symptoms or infection were done for all patients up to 6 months.

\section{Statistical analysis:}

Patients' data were presented as frequency and percentage for categorical variables, mean and SD for numerical variables. Groups were compared by independent samples Student $t$-test and $\chi^{2}$-test for numerical and categorical data, respectively. All data and statistical analyses were handled by statistical package for the social sciences (SPSS, IBM, SPSS Inc. Chicago, USA) computer package version 18.

\section{Results}

The demographic data of the included patients are shown in Table (1).
Table (1): Demographic data of studied cases.

\begin{tabular}{lc}
\hline Mean \pm SD & Patients $(\mathrm{N}=500)$ \\
\hline Age (years) & $41.82 \pm 7.65$ \\
Gender (Male/Female) & $170 / 330$ \\
Percentage of male (\%) & $34 \%$ \\
Body Mass index (BMI) $\left(\mathrm{kg} / \mathrm{m}^{2}\right)$ & $29.8 \pm 5.129$ \\
\hline
\end{tabular}

Table (2) shows that $20(4 \%)$ of cases were found to have been falling in the age group (20$30)$ years, $200(40 \%)$ of them were falling in the age group (31-40), $220(44 \%)$ had an age ranged between (41-50) years, whereas $60(12 \%)$ of patients were in the age group 51-60 years, The mean age was $41.82 \pm 7.65$ years.

Table (2): Distribution of the studied cases according to age.

\begin{tabular}{lcc}
\hline Age & Frequency(N) & Percentage \\
\hline $20-30$ & 20 & 4 \\
$31-40$ & 200 & 40 \\
$41-50$ & 220 & 44 \\
$51-60$ & 60 & 12 \\
\hline Total & 500 & 100 \\
\hline
\end{tabular}


In this study, 170 males (34\%) and 330 female $(66 \%)$ were recruited, with the mean body mass index was 29.8 \pm 5.129 (Table 3).

Table (3): Distribution of the studied cases according to gender.

\begin{tabular}{lcc}
\hline Sex & Frequency & Percent \\
\hline Male & 170 & 34 \\
Female & 330 & 66 \\
& & \\
\hline Total & 500 & 100 \\
\hline
\end{tabular}

Ultrasound was done as a routine investigation in all patients. All of the five hundred patients had stones in gallbladder, 380 of them $(76 \%)$ had small GB stones while 120 (24\%) had large GB stones. Also, 370 cases had multiple stones whereas 130 (26\%) had solitary stones and $50(10 \%)$ had impacted stones. Furthermore, out of 500 cases, 40 (8\%) had distended GB, 50 (10\%) had Pericholecystic collection, 70 (14\%) had GB wall thickening, $30(6 \%)$ had Cirrhotic liver and $60(12 \%)$ had bright fatty liver.

Table (4): Ultrasonography finding in the studied cases.

\begin{tabular}{lll}
\hline Ultrasonographic data & Frequency & Percent \\
\hline GB distension: & 460 & 92 \\
$\quad$ Normal & 40 & 8 \\
$\quad$ Distended & 50 & 10 \\
Pericholecystic collection & 70 & 14 \\
GB Wall thickness $\geq 4 \mathrm{~mm}$ & & \\
GB stone size: & 380 & 76 \\
$\quad$ Small & 120 & 24 \\
$\quad$ Large & & \\
GB stone number: & 130 & 26 \\
$\quad$ Solitary & 370 & 74 \\
$\quad$ Multiple & 50 & 10 \\
Impacted stone in the neck of GB & & \\
Liver ultrasonography finding: & 410 & 82 \\
$\quad$ Average & 60 & 12 \\
$\quad$ Fatty & 30 & 6 \\
$\quad$ Cirrhotic &
\end{tabular}

As shown in Table (5), out of 500 patients included in this study 111 patients mild and moderate adhesion and inflammation in the Calot's triangle and 44 patients had adhesion burying the gall bladder. Also, $40(8 \%)$ cases had distended gall bladder, 35 (7\%) cases suffered from stone $\geq 1 \mathrm{~cm}$ impacted in Hartman's pouch, $42(8.4 \%)$ patients had difficulty in access to peritoneal cavity.
Table (5): Intra-operative parameters among studied cases.

\begin{tabular}{lll}
\hline & Frequency & Percent \\
\hline Appearance: & & \\
- No adhesion and inflammation & 345 & 69 \\
- Mild adhesion and inflammation & 75 & 15 \\
- Moderate adhesion and inflammation & 36 & 7.2 \\
- Adhesion and Sever inflammation & 44 & 8.8 \\
$\quad$ burying the gall bladder & & \\
GB (contraction/distention): & & \\
- No & 385 & 77 \\
- Contarcted & 10 & 2 \\
- Distended & 40 & 8 \\
- Stone $\geq 1 \mathrm{~cm}$ impacted in Hartman's & 35 & 7 \\
$\quad$ pouch & 30 & 6 \\
- Unable to grasp with atraumatic & & \\
$\quad$ laproscopic forceps & & \\
$\begin{array}{l}\text { Access to peritoneal cavity: } \\
\text { - No }\end{array}$ & 458 & 91.6 \\
- Adhesion pervious surgery & 42 & 8.4 \\
$\quad$ limiting access & & \\
\hline
\end{tabular}

There were 420 patients out of 500 patients of study group that were straigh forward operation with acheivement the CVS, 345 cases $69 \%$ had no adhesions and (75) cases $15 \%$ had mild adhesions. There were intraoperative mild bleeding in (21) cases $4.2 \%$ from visceral injury to the liver during insertion of the second port causing mild bleeding which has been stopped without any intervention, vascular injury to the abdominal wall during port insertion (port site bleeding) which had stopped by cauterization to the bleeding peritoneal surface and bleeding during dissection controlled with compression and bipolar coagulations. Postoperative bleeding (4) cases $0.8 \%$ were diagnosed early post operatively by detecting continuous bleeding through the drain in the 1 st post operative day $200 \mathrm{cc}$. It managed conservatively by close observation to the patient, in the 2 nd day it reduced to $100 \mathrm{cc}$ then stopped the drain removed 3 days after complete stoppage.

There were $40(8 \%)$ patients out of 500 patients of study group converted to open procedure, they had moderate and severe adhesions during the laparoscopic cholycestectomy. There was severe bleeding during the dissection and injury to cystic artery in (18) cases $3.6 \%$ lead to convert to open, and (2) cases $0.4 \%$ had bile duct injury which had managed intraoperative by conversion to open procedure; the two cases were Strasberg type D (lateral injury to the common bile duct) and managed by primary closure over a $\mathrm{T}$ tube. Factors lead to convertion to open: 15 cases had single factor, 12 cases had severe adhesions and 3 cases had moderate adhesions. 25 cases had combined factors, 18 cases had severe bleeding with moderate 
adhesions, 2 cases had bile duct injury with moderate adhesions and 5 cases had mild bleeding with moderate adhesions. Three cases $0.6 \%$ had postoperative mild bleeding, the drain in the 1 st post operative day was $150 \mathrm{cc}$. There managed conservatively by close observation to the patient, in the 2 nd day it reduced to $100 \mathrm{cc}$ then stopped the drain removed 3 days after complete stoppage. Two cases $0.4 \%$ had postoperative Biliary leakage which managed conservative treatment it was minor leakage. Post operative (port site) wound infections were in (13) cases $2.6 \%$ had managed early post operatively by IV antibiotic and daily wound dressing.

Table (6): Statement of Standard laparoscopic with acheivement of CVS Figs. (2,3), intra and post operative complication.

\begin{tabular}{|c|c|c|}
\hline Achieved Straight Forward CVS & 420 & $84 \%$ \\
\hline \multicolumn{3}{|l|}{ Appearance: } \\
\hline \multicolumn{3}{|l|}{ - Adhesion and inflammation } \\
\hline - (No) & 345 & $69 \%$ \\
\hline - (Mild) & 75 & $15 \%$ \\
\hline - (Moderate) & 0 & \\
\hline - (Severe) & 0 & - \\
\hline \multicolumn{3}{|l|}{ Intra OP Complications: } \\
\hline \multicolumn{3}{|l|}{ - Bleeding } \\
\hline - (No) & 399 & $79.8 \%$ \\
\hline - (Mild) & 21 & $4.2 \%$ \\
\hline - (Severe) & 0 & \\
\hline \multicolumn{3}{|l|}{ - Bile duct injury } \\
\hline - (Yes) & 0 & \\
\hline - $(\mathrm{No})$ & 420 & $84 \%$ \\
\hline \multicolumn{3}{|l|}{ - Gall bladder perforation } \\
\hline - (Yes) & 5 & $1 \%$ \\
\hline - (No) & 415 & $83 \%$ \\
\hline \multicolumn{3}{|l|}{ Post OP Complications: } \\
\hline \multicolumn{3}{|l|}{ - Biliary leakage } \\
\hline - (Yes) & 5 & $1 \%$ \\
\hline - (No) & 415 & $83 \%$ \\
\hline \multicolumn{3}{|l|}{ - Bleeding } \\
\hline - (Yes) & 4 & $0.8 \%$ \\
\hline - (No) & 416 & $83.2 \%$ \\
\hline \multicolumn{3}{|l|}{ - Jaundice } \\
\hline - (Yes) & 1 & $0.2 \%$ \\
\hline - (No) & 419 & $83.8 \%$ \\
\hline \multicolumn{3}{|l|}{ - Post OP Infection } \\
\hline - (Yes) & 10 & $2 \%$ \\
\hline - (No) & 410 & $82 \%$ \\
\hline Average Time Taken & $60: 90$ minutes & \\
\hline Average Hospital Stay Time & 1-2 days & \\
\hline
\end{tabular}

Table (7): Statement of Convertion to open, intra and post operative complication.

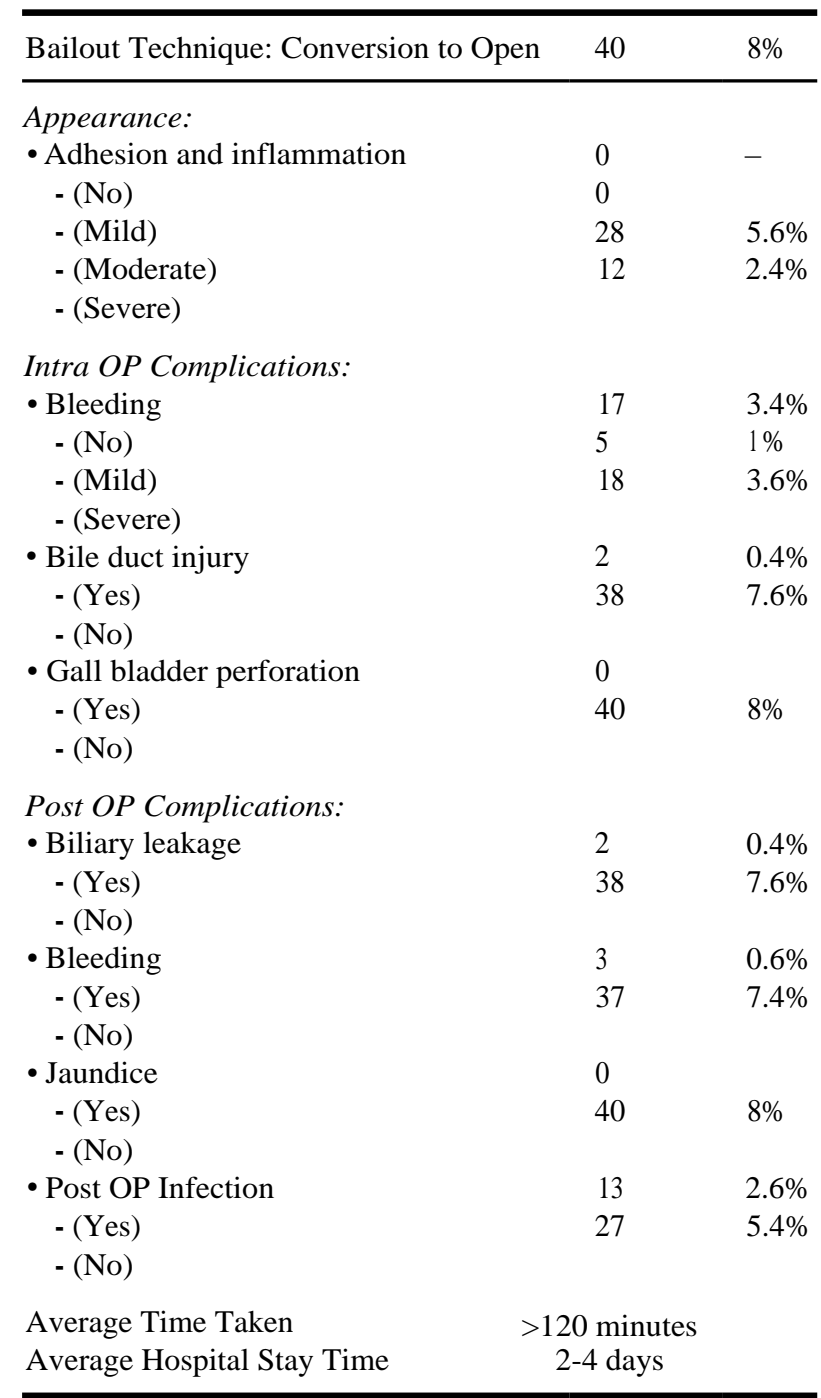

There were 30 cases out of 500 cases of study group that subtotal cholycystectomy done as abailout technique, (28) cases $5.6 \%$ had dense adhesions and two cases $0.4 \%$ had moderated adhesion in the Calot's triangle that burying the gall bladder. There was intraoperative mild bleeding in (7) cases $1.4 \%$ from bed of GB which has been stopped by compression and cauterization. Six cases $1.2 \%$ had post operative mild bleeding (port site bleeding, bleeding from bed of GB) which passed with conservative treatment. 17 cases $(3.4 \%)$ had post operative (port site) wound infection which had managed by IV antibiotic and daily wound dressing. Post-operative biliary leakage were in (2) cases $0.4 \%$ they managed with conservative treatment, there were minor leakage. Post operative jaundice was in one case $0.2 \%$ diagnosed and MRCP done found that Strasberg type El injury (false ligation of the common bile duct) and managed by Choledocho jejunostomy in high center. 
Table (8): Statement of Subtotal cholecystectomy as abailout technique, intra and post operative complication.

\begin{tabular}{|c|c|c|}
\hline $\begin{array}{l}\text { Bailout Technique: } \\
\text { SubTotal Cholecystectomy }\end{array}$ & 30 & $6 \%$ \\
\hline \multicolumn{3}{|l|}{ Appearance: } \\
\hline \multicolumn{3}{|l|}{ - Adhesion and inflammation } \\
\hline - (No) & 0 & \\
\hline - (Mild) & 0 & \\
\hline - (Moderate) & 2 & $0.4 \%$ \\
\hline - (Severe) & 28 & $5.6 \%$ \\
\hline \multicolumn{3}{|l|}{ Intra OP Complications: } \\
\hline \multicolumn{3}{|l|}{ • Bleeding } \\
\hline - (No) & 23 & $4.6 \%$ \\
\hline - (Mild) & 7 & \\
\hline - (Severe) & 0 & \\
\hline \multicolumn{3}{|l|}{ - Bile duct injury } \\
\hline - (Yes) & 0 & - \\
\hline - $(\mathrm{No})$ & 30 & $0 \%$ \\
\hline \multicolumn{3}{|l|}{ Post OP Complications: } \\
\hline \multicolumn{2}{|l|}{ - Biliary leakage } & $0.4 \%$ \\
\hline $\begin{array}{l}-(\text { Yes }) \\
-(\mathrm{No})\end{array}$ & 28 & $5.6 \%$ \\
\hline \multicolumn{3}{|l|}{ •Bleeding } \\
\hline - (Yes) & 6 & $1.2 \%$ \\
\hline - (No) & 24 & $4.8 \%$ \\
\hline \multicolumn{3}{|l|}{ - Jaundice } \\
\hline - (Yes) & 1 & $0.2 \%$ \\
\hline - (No) & 29 & $5.8 \%$ \\
\hline \multicolumn{3}{|l|}{ - Post OP Infection } \\
\hline - (Yes) & 13 & $2.6 \%$ \\
\hline & & \\
\hline Average Time Taken & $>120$ minutes & \\
\hline Average Hospital Stay Time & 2-4 days & \\
\hline
\end{tabular}

There were (7) cases $1.4 \%$ had moderate and severe adhesions where fundus $1 \mathrm{st}$ technique done as abailout technique. Intra operative mild bleeding from bed of GB and tear in cystic artery in (3) cases $0.6 \%$ that controlled with appling clips and cauterization. Gall bladder perforation in one case. Post-operative Biliary leakage was in one case $0.2 \%$ managed with conservative treatment it was minor leakage. Post operative Mild bleeding were in (2) $0.4 \%$ (port site bleeding, bleeding from bed of GB) it passed conservative. No post operative Jaundice was detected. Post-operative (port site) wound infection was in one case $(0.2 \%)$ had managed by IV antibiotic and daily wound dressing.
Table (9): Statement of Fundus First, intra and post operative complication.

Bailout Technique:

Fundus First Cholecystectomy

7

$1.4 \%$

Appearance:

- Adhesion and inflammation

- (No)

0

- (Mild)

- (Moderate)

- (Severe)

Intra OP Complications:

- Bleeding

- (No)

$0.4 \%$

- (Mild)

$0.6 \%$

- (Severe)

\section{4}

3

0

- Bile duct injury

- (Yes)

- (No)

- Gall bladder perforation

- (Yes)

- (No)

Post OP Complications:

- Biliary leakage

- (Yes)

$0.2 \%$

- (No)

$1.2 \%$

- Bleeding

- (Yes)

$0.4 \%$

- (No)

- Jaundice

- (Yes)

- (No)

- Post OP Infection

- (Yes)

- (No)

Average Time Taken

Average Hospital Stay Time

90: 120 minutes 2-3 days

Out of 500 patients, there were three cases $0.6 \%$ had done tube Cholecystostomy, those patients we can't did laparoscopic cholecystectomy and abort the procedure due to very bad condition in addition to severe adhesions, impending rupture and pyocele of gall bladder, for drainage and gall bladder dcompersion. Those three cases had done interventional tube Cholecystostomy, two cases by ultrasound guided and one done surgically. 
Table (10): Statement of tube Cholecystostomy, intra and post-operative complication.

\begin{tabular}{|c|c|c|}
\hline $\begin{array}{l}\text { Bailout Technique: } \\
\text { Cholecystostomy Tube }\end{array}$ & 3 & $0.6 \%$ \\
\hline \multicolumn{3}{|l|}{$\begin{array}{l}\text { Appearance: } \\
\text { - Adhesion and inflammation }\end{array}$} \\
\hline - (No) & 0 & - \\
\hline - (Mild) & 0 & - \\
\hline - (Moderate) & 0 & \\
\hline - (Severe) & 3 & $0.6 \%$ \\
\hline \multicolumn{3}{|l|}{$\begin{array}{l}\text { Intra OP Complications: } \\
\text { - Bleeding }\end{array}$} \\
\hline - (No) & 3 & $0.6 \%$ \\
\hline - (Mild) & 0 & - \\
\hline - (Severe) & 0 & - \\
\hline \multicolumn{3}{|l|}{ - Bile duct injury } \\
\hline - (Yes) & 0 & \\
\hline - (No) & 3 & $0.6 \%$ \\
\hline \multicolumn{3}{|l|}{ Post OP Complications: } \\
\hline - (Yes) & 0 & \\
\hline - (No) & 3 & $0.6 \%$ \\
\hline \multicolumn{3}{|l|}{ - Bleeding } \\
\hline - (Yes) & 0 & \\
\hline - (No) & 3 & $0.6 \%$ \\
\hline \multicolumn{3}{|l|}{ - Jaundice } \\
\hline - (Yes) & 0 & \\
\hline - (No) & 3 & $0.6 \%$ \\
\hline \multicolumn{3}{|l|}{ - Post OP Infection } \\
\hline - (Yes) & 1 & $0.2 \%$ \\
\hline - (No) & 2 & $0.4 \%$ \\
\hline Average Time Taken & $>120$ minutes & \\
\hline Average Hospital Stay Time & 2-4 days & \\
\hline
\end{tabular}

\section{Discussion}

Laparoscopic cholecystectomy (LC) is currently and worldwide considered the gold standard for the treatment of gallbladder cholithiasis. Since its introduction, in the early 1990s, this procedure has gained a remarkable consensus until becoming a routine surgical procedure. LC is characterized by a reduction in postoperative pain, hospital stay and recovery times to normal daily activities, which translates into reduced costs for the national healthcare systems (NHS). However, this procedure comes with an increased incidence of bile duct injuries (BDI), compared to open cholecystectomy (OC): $0.3 \%$ to $0.8 \%$ vs $0.2 \%$ [13]

LC-related BDIs include minor injuries up to complex hilar injuries, as classified by Strasberg et al., in which the most severe types correspond to type $\mathrm{E}$ injuries including ongoing stricture, complete occlusion and resection or division of the bile ducts. The management of BDI may require additional treatments ranging from endoscopic retrograde cholangiopancreatography (ERCP) to restorative surgery, up to hepatic transplantation in selected cases, leading to a significant increase in postoperative morbidity, mortality, and costs. Risk factors of BDI can be divided in patient and surgery related [14].

Although the focus in the current literature has been on biliary complications of LC, the risk of intraoperative bleeding has also been reported with a variable incidence in many series and case reports. Intra- or postoperative bleeding in case of LC represents an important, complication ranging from minor hematomas to significant bleeds (missed operative injuries, portside bleeding, clips over cystic artery) potentially requiring blood transfusion or re-intervention. It has been reported as the most frequent cause of procedure-related mortality in LC (after anesthesia-related deaths) [15]

The corner stone for performing a safe cholecystectomy include an adequate knowledge of normal anatomy and related variants, an identification of predictive factors for difficult surgery, and the employment of a correct technique. Since the introduction of laparoscopy, the "infundibular" technique (IT) and the intraoperative recognition of cystic duct and gallbladder junction for gallbladder hilar dissection have been primarily used. In alternative to IT, Strasberg introduced in 1995 the "Critical View of Safety" (CVS) to promote the recognition of the gallbladder elements to reduce the risk of BDI and to avoid mistakes due to anatomical alterations and altered visual perception [9].

The importance of the CVS was also recently recognized by the Society of American Gastrointestinal and Endoscopic Surgeons (SAGES), who encouraged the use of this technique in the "Safe Cholecystectomy Program" to minimize BDI risk and promoted the adoption of a universal culture of safety in cholecystectomy. However, despite the widespread use of CVS, a significant BDI decrease has not yet been recorded. Moreover, the scientific evidence supporting this technique to prevent BDI is controversial. Several studies, indeed, suggest that the regular use of CVS can reduce or eliminate the risk of BDI. Other studies contrast the widespread consensus for the technique in the scientific community, showing that CVS is not associated with a useful and correct application in clinical practice [16].

There are five bailout strategies for a difficult gallbladder: (1) Abort the procedure altogether; 
(2) Convert to an open procedure; (3) Tube cholecystostomy; (4) Subtotal cholecystectomy (STC, open/laparoscopic); and (5) Fundus first cholecystectomy [17].

The main aim of this study was to verify of the use of the critical view of safety during laparoscopic cholecystectomy in a rural hospital regarding safety, efficacy of the technique, difficulties during the technique, operative time and postoperative outcome at early learning curve and bailout techniques to do safe cholecystectomy.

A retrospective study was conducted in Kafr El Sheikh General Hospital included 500 patients who were presented with symptomatic cholelithiasis who were fit for laparoscopic cholecystectomy under general anesthesia. The duration of the study was one year between (1-1-2019) - (1-1-2020). Detailed clinical history was obtained that included demographic data consisting of age, sex and obesity, history of previous hospitalization for acute cholecystitis, history of ERCP and comorbid diseases (diabetes, or elevated liver enzymes etc). Diagnosis of cholelithiasis was confirmed in patients presenting with abdominal symptoms using an abdominal ultrasonography (USG).

\section{The main results of this study were as following:}

The mean age of the studied group was 42 years. The majority of them $(66 \%)$ were females and (34\%) males. The mean BMI was 29.8 and $38 \%$ of them had DM.

In most literature, there female predominance in LC operation as the female gender has a most compelling association with gallstone disease, especially during the fertile years. Women are almost twice as likely as men to form stones [18]

The advantages of laparoscopic cholecystectomy in the early 1990 s led to a paradigm change and shift from open approach towards minimally invasive techniques. Meanwhile, the laparoscopic cholecystectomy is now the most common laparoscopic procedure performed in general surgery and considered to be the gold standard in the treatment of symptomatic cholelithiasis and acute/chronic cholecystitis [3].

In our study acheivment of CVS was (84\%), there were postoperative biliary leakage in this standard technique in $(1 \%)$ in form of Strasberg (type A) as aminor injury, in difficult cases which achievement of CVS were difficult bailout techniques done as convertion to open where they had bile duct injury intra operative $(0.4 \%)$, subotal cholecystectomy post operative biliary leakage was $(0.4 \%)$ in form of Strasberg (type A), bile duct injury was $(0.2 \%)$ in form of Strasberg (type E1) post operative and fundus ${ }^{1 \text { st }}$ technique post operative biliary leakage was in one case $(0.2 \%)$ in form of Strasberg (type A) as minor injury.

According to Dziodzio et al., [11], in the case presented, transection of the common bile duct was prevented through critical examination of the CVS. However, the importance of the CVS shall not be touted as a dogma. Instead, we recommend to use it as a framework, which shall help the surgeon to re-evaluate each surgical step before proceeding. Different anatomies can lead to misinterpretations and lead to pitfalls in hasty preparation situations. Injuries of the common bile duct are the most frequent bile duct injuries described in literature ranging from $66 \%$ to $72 \%$ of all bile duct lesions [19]

Buddingh et al., [20] stated that the criticalview-of-safety approach, directly establishing biliary anatomy, is accepted by most guidelines and considered as the surgical technique of choice to minimize BDI risk.

In another study of Buddingh et al., [20], the critical view of safety (CVS) technique is used by $97.6 \%$ of the surgeons. It is documented by $92.6 \%$, mostly in the operation report $(80.0 \%)$, but often augmented by photography $(42.7 \%)$ or video $(30.2 \%)$. If the CVS is not obtained, $50.9 \%$ of surgeons convert to the open approach, $39.1 \%$ continue laparoscopically, and $10.0 \%$ perform additional imaging studies.

Cholecystectomy is one of the most frequently performed operations in the Western world, with over 750,000 yearly in the United States alone. Bile duct injury (BDI) is a greed complication of cholecystectomy. When the laparoscopic technique was introduced in the early 1990s an increase of BDI was noted from approximately $0.2 \%$ to about $0.5 \%$. The burden of BDI on patients is considerable. Reinterventions through surgical, endoscopic, or radiologic procedures in specialized centers are frequently necessary. A recent study reported that BDI had a significant negative effect on quality of life even 10 years after the event. BDI is also associated with substantial financial burden for the health-care system: A British study calculated an average cost of 108,000£ ( 175,000 \$US) for major BDI (hospital and society costs) [21]

During laparoscopic cholecystectomy the primary cause of BDI is an error of visual perception (in 71-97\% of cases), not insufficient technical skill of the surgeon. Factors that impede visual 
assessment and increase the risk of BDI include past or ongoing inflammation, variant ductal anatomy, and limited surgical experience. It was reported that to minimize biliary injuries, the (CVS) should be obtained in every patient during laparoscopic cholecystectomy, regardless of difficulty during dissection of Calot's triangle. As it is a safe, effective and easily applied method even by junior surgeons with limited laparoscopic experience, so should be established as the standard in training for laparoscopic cholecystectomy [22] .

The present study showed that the mean operative time was (90-120) minutes. In CVS the mean operative time was (75) minutes, in cases of convertion to open was $>120$ minutes, in cases of subtotal cholecysetectomy was $>120$ minutes and in cases of fundus 1 st technique was 120 minutes. There were (54) $10.8 \%$ of the studied group had intra operative bleeding, there were severe bleeding with moderate adhesion in (18) casas $3.6 \%$ and five cases $1 \%$ had mild bleeding with moderate adhesion that managed with convertion to open. there were $(31)$ cases $6.2 \%$ of the studied group had mild bleeding managed with compession, reevaluation, bipolar coagulations and clip applications. Post operative mild bleeding was in (15) cases 3\% managed conservatively, convertion rate due to intra operative bleeing, bile duct injury and adhesions in gall bladder and hepatocystic triangle was $8 \%$.

Our results were supported by study of Sgaramella et al., [23] as they reported that the study population was divided into two groups according to the evidence (Group A; $n=11$ ) or (Group B; $\mathrm{N}=593$ ) absence of BDI and perioperative bleeding. The non-use of CVS was found in $54.6 \%$ of procedures in the Group A, and $25.8 \%$ in the Group $\mathrm{B}$, and evaluating the operator-related variables the execution of CVS was associated with a significantly lower incidence of BDI and intraoperative bleeding. During the enrolment period, all involved centres registered a conversion rate ranging from 3 to $9 \%$ (average: $4.9 \%$ ), and the most common reasons were the need for $\mathrm{CBD}$ exploration due to the altered Calot's triangle anatomy, BDI, and/or intraoperative bleeding. Conversion to open surgery were caused by BDI in 5 patients $(14.3 \%$ of converted cases) and bleeding in one case (2.8\%). No morality detected in preoperative period.

Our results were supported by study of Sgaramella et al., [23] as they reported that among the cohort of 604 patients analysed, $8(1.3 \%)$ cases presented bleeding that was conservatively managed. However, the duration of surgery exceeded 60min (range: $25-240 \mathrm{~min}$ ).
In the study in our hands the percentage of conversion was line with the conversion rate $8 \%$, this percentage of conversion was line with the conversion rate that is reported to be between 3 and $24 \%$ [24]

The overall conversion rate in a study conducted by Nidoni et al., [25] was also $6 \%$.

In the study of Vettoretto et al., [3], there were 2 patients had intraoperative hemorrhages, both controlled with bipolar coagulations and clip applications; 1 of the 2 patients required blood transfusions. Significant differences were found in the operative times. Both median times (51.5 min vs $69.7 \mathrm{~min}$ ) and average time divided by casedifficulty (defined by different grades of gallbladder inflammation) were in favor of the CVS approach. They compared the critical view of safety triangle approach with the infundibular approach in their retrospective cohort study.

However, Heistermann et al., [26] demonstrated that the mean operation time was 81 minutes.

The laparoscopic technique results in lower postoperative pain, shorter hospital stays and a proper cosmesis. In times before the laparoscopic era the incidence of biliary injuries after conventional open cholecystectomy amounted $\sim 0.2 \%$. However, despite of contemplated advantages, a rapid learning curve and constant improvements in methodology, the complication rates of bile duct injuries after laparoscopic cholecystectomy count from $0.4 \%$ to $0.5 \%$, dependent on the underlying disease and remain higher than in the open approach. The most common cause of serious biliary injury is misidentification [9].

Due to above mentioned significant divergence between open and laparoscopic procedures Strasberg and colleagues in 1995 first suggested a three steps strategy called the "critical view of safety" (CVS), to minimize the risk of bile duct injuries in laparoscopic cholecystectomy [27].

In the study of Vettoretto et al., [3], no mortalities occurred in the series. Morbidity was $0.1 \%$ (1 patient) in group 1 and $0.2 \%$ in group 2 (2 patients). One biliary leak from the cystic duct in the first patient (acute gangrenous cholecystitis) resolved after an endoscopic sphincterotomy was performed on postoperative day 1 .

The Strasberg's CVS was introduced with the purpose to overcome errors of interpretation of the visual field during dissection of the elements of the gallbladder, and this is supported by several 
studies showing that the routinely use of CVS is associated with a reduction or even elimination of BDI. The safety of the maneuver described by Strasberg is confirmed by the present study in which it is found as a significant protective factor to prevent $\mathrm{BDI}$ and/or hemorrhagic complications.

Avgerinos et al., analyzed 1,046 patients who underwent LC. No BDI occurred in 998 cases when CVS was performed [10]

Although the aim of CVS is to reduce BDI during $\mathrm{LC}$, there was no decrease in countries where its use has now become mandatory. Therefore, it has been hypothesized that CVS is useful in preventing major lesions (Type E) due to proper recognition of the anatomy, but fails to avoid injuries type A such as biliary fistulas. This is reflected in this study, in which a complete lesion of the major bile ducts located $>2 \mathrm{~cm}$ from the upper biliary confluent (type E 1) is reported among the non-Strasberg group [28]

When the CVS cannot be safely obtained during dissection of Calot's triangle, conversion to open surgery is advocated to prevent bile duct injury. However, there is a wide variation in the current literature of the conversion rate to open surgery and, in accordance with this reported experience, it ranges from 2 to $15 \%$ [29].

According to Al Masri et al., [30], surgeryrelated indications for conversion includes extensive adhesions, significant inflammation, intraoperative difficulty of bile ducts exploration, and major bleeding. Medical comorbidities (such as pulmonary disease) have been furthermore found to be a risk factor for conversion from laparoscopic to open surgery in different series and for different laparoscopic procedures.

In the study in our hands, the mean length of hospital stay was 2 days. The Achievement of Critical View of safety was (84\%).

Our results were supported by study of Sgaramella et al., [23] as they reported that the correct application of CVS was observed in $73.7 \%(n=445)$ of LC, whereas the non-use of CVS was found in $26.3 \%(n=159)$.

Also, Daly et al., [31] reported that in total, 374 of 849 surgeons responded. The CVS was not correctly identified by $75 \%$ of surgeons descriptively and by $21 \%$ of surgeons visually.

Furthermore, van de Graaf et al., [16] reported that $98.2 \%$ of the respondents indicated incorporating the Critical View of Safety technique into current practice. However, only $72 \%$ of respondents performed the essential steps of the Critical View of Safety technique frequently. Subsequently, half of respondents were able to identify the corresponding steps of the Critical View of Safety technique, and only $16.9 \%$ were able to distinguish these adequately from possible harmful steps.

In the study of Zhang et al., [29], 53 of the 100 primary laparoscopic operated patients showed the signs of an acute cholecystitis. Only in 3 patients it was not possible to apply the "critical view of safety" resulting in a conversion to open cholecystectomy. Postoperative hospital stay ranged to 5.4 (1-18) days.

\section{Conclusion:}

The Critical View of Safety, when correctly applied, is confirmed to be the safest technique for recognizing the elements of the hepatocystic triangle, and it is associated with a significant impact in preventing intraoperative and postoperative complications (iatrogenic injuries and perioperative bleeding). In situations in which there is severe inflammation and adhesions in the porta hepatis and neck of the gallbladder, the CVS can be difficult to achieve, Consideration of laparoscopic subtotal cholecystectomy or cholecystostomy tube placement or laparoscopic fundus technique or conversion to an open procedure as different options for abailout techniques based on the judgment of the attending surgeon and senior staff on the operating room. In order to increase our learning skills in basic and advanced laparoscopic procedures with achievement of high learning curve, we need continuous medical education with workshop attendance and pelvitraining.

\section{References}

1- ABD-EL-AAL A.S. and ABDALLAH H.A.: Evaluation of preoperative predictive factors for difficult laparoscopic cholecystectomy in comparison with intraoperative parameters. The Egyptian Journal of Surgery, 37 (4): $504-$ 511,2018 .

2- BUSTOS B.I., PÉREZ-PALMA E., BUCH S., AZÓCAR L., RIVERAS E., UGARTE G.D., TOLIAT M., NÜRNBERG P., LIEB W., FRANKE A. and HINZ S.: Variants in ABCG8 and TRAF3 genes confer risk for gallstone disease in admixed Latinos with Mapuche Native American ancestry. Scientific Reports, 9 (1): 1-12, 2019.

3- VETTORETTO N., SARONNI C., HARBI A., BAL ESTRA L., TAGLIETTI L. and GIOVANETTI M.: Critical view of safety during laparoscopic cholecystectomy. JSLS, 15: 322-325, 2011.

4- FEIGEL A. and PATRICIA SYLLA: Role of Minimally Invasive Surgery in the Reoperative Abdomen or Pelvis. Clin. Colon. Rectal. Surg., 29 (2): 168-180, 2016. 
5- ADAMSEN S., HANSEN O.H., FUNCH-JENSEN P., SCHULZE S., STAGE J.G. and WARA P.: Bile duct injury during laparo-scopic cholecystectomy: A prospective nationwide series. J. Am. Coll. Surg., 184: 571-8, 1997.

7- VOLLMER C.M. and CALLERY M.P.: Biliary injury following laparoscopic cholecystectomy: Gastroenterology, 133: 1039, 2007.

8- GHANEM Y.B., FAHMY K.S. and REFAAT D.O.: Preoperative prediction of difficult laparoscopic cholecystectomy: In Zagazig University Hospitals. Zagazig University Medical Journal, 23 (4): 208-220, 2017.

9- STRASBERG S.M. and BRUNT L.M.: Rationale and use of the critical view of safety in laparoscopic cholecystectomy. The Journal of the American College of Surgeons (JACS), 211: 132-138, 2010.

10- AVGERINOS C., KELGIORGI D., TOULOUMIS Z., BALTATZI L. and DERVENIS C.: One thousand laparoscopic cholecystectomies in a single surgical unit using the "critical view of safety" technique. J. Gastrointest Surg., 13: 498-503, 2009.

11- DZIODZIO T., WEISS S., SUCHER R., PRATSCHKE J. and BIEBL M.: A 'critical view'on a classical pitfall in laparoscopic cholecystectomy! International journal of surgery case reports, 5 (12): 1218-1221, 2014.

12-MANATAKIS D., VITALIS A., AGALIANOS C., TERZIS I., KYRIAZANOS I. and DAVIDES D.: Teaching and learning the critical view of safety technique in laparoscopic cholecystectomy. HPB, 18 (S2): 665-666, 2016.

13-TÖRNQVIST B., STRÖMBERG C., PERSSON G., NILSSON M.: Effect of intended intraoperative cholangiography and early detection of bile duct injury on survival after cholecystectomy: Population-based cohort study. British Medical Journal, 345: e6457, 2012.

14- McKINLEY S.K., BRUNT L.M. and SCHWAITZBERG S.D.: Prevention of bile duct injury: The case for incorporating educational theories of expertise. Surg. Endosc., 28 (12): 3385-3391, 2014.

15-GUPTA V., GUPTA V., JOSHI P., KUMAR S., KULKAR NI R., CHOPRA N., et al.: Management of post cholecystectomy vascular injuries. Surgeon, 17 (6): 326-333, 2019.

16- van de GRAAF F.W., van den BOS J., STASSEN L.P and LANGE J.F.: Lacunar implementation of the critical view of safety technique for laparoscopic cholecystectomy: Results of a nationwide survey. Surgery, 164 (1): 31-39, 2018;.

17- SANTOS B.F., BRUNT L.M. and PUCCI M.J.: The Difficult Gallbladder: A Safe Approach to a Dangerous Problem. Journal of Laparoendoscopic \& Advanced Surgical Techniques, 27: 571-578, 2017.

18- STINTON L.M. and SHAFFER E.A.: Epidemiology of gallbladder disease: Cholelithiasis and cancer. Gut and liver, 6 (2): 172-178, 2012.

19- ARCHER D.W., BROWN C.D., SMITH G.D. and BRANUM J.G.: Bile duct injury during laparoscopic cholecystectomy: Results of a National Survey Ann. Surg., 234: 549-558, 2001.

20- BUDDINGH K.T., NIEUWENHUIJS V.B., VAN BUUREN L., HULSCHER J.B., de JONG J.S. and VAN DAM G.M.: Intraoperative assessment of biliary anatomy for prevention of bile duct injury: A review of current and future patient safety interventions. Surg. Endosc., 25: 2449-2461, 2011.

21- ALKHAFFAF B. and DECADT B.: 15 years of litigation following laparoscopic cholecystectomy in England. Ann. Surg., 251: 682-685, 2010.

22- WAY L.W., STEWART L., GANTERT W., LIU K., LEE C.M., WHANG K. and HUNTER J.G.: Causes and prevention of laparoscopic bile duct injuries: Analysis of 252 cases from a human factors and cognitive psychology perspective. Ann. Surg., 237: 460-469, 2003.

23- SGARAMELLA L.I., GURRADO A., PASCULLI A., de ANGELIS N., MEMEO R., PRETE F.P. and SOLARI N. The critical view of safety during laparoscopic cholecystectomy: Strasberg Yes, or No? An Italian Multicentre study. Surgical Endoscopy, 1-11, 2020.

24- AKCAKAYA A., OKAN I., BAS G., SAHIN G., SAHIN M.: Does the difficulty of laparoscopic cholecystectomy differ between genders? Indian Journal of Surgery, 77 (2): 452-456, 2015.

25- NIDONI R., UDACHAN T.V., SASNUR P., BALOORKAR R., SINDGIKAR V. and NARASANGI B.: Predicting difficult laparoscopic cholecystectomy based on clinicoradiological assessment. Journal of Clinical and Diagnostic Research: JCDR, 9 (12): PC09-PC12, 2015.

26- HEISTERMANN, TOBUSCH A. and PALMES D.: The "safety view" as a contribution to reducing the risk of laparoscopic cholecystectomy. Zentralbl Chir., 131 (6): 460-465, 2006.

27- STRASBERG S.M., HERTL M. and SOPER N.J.: An analysis of the problem of biliary injury during laparoscopic cholecystectomy. The Journal of the American College of Surgeons (JACS), 180: 101-125, 1995.

28- STEFANIDIS D., CHINTALAPUDI N., ANDERSONMONTOYA B., OOMMEN B., TOBBEN D. and PIMEN TEL M.: How often do surgeons obtain the critical view of safety during laparoscopic cholecystectomy? Surg. Endosc., 31 (1): 142-146, 2017.

29- ZHANG W.J., LI J.M., WU G.Z., LUO K.L. and DONG Z.T.: Risk factors affecting conversion in patients undergoing laparoscopic cholecystectomy. ANZ J. Surg., 78 (11): 973-976, 2008.

30- AL MASRI S., SHAIB Y., EDELBI M., TAMIM H., JAMALI F., BATLEY N., et al.: Predicting conversion from laparoscopic to open cholecystectomy: A single institution retrospective study. World J. Surg., 42 (8): 2373-2382, 2018.

31- DALY S.C., DEZIEL D.J., LI X., THAQI M., MILLIKAN K.W., MYERS J.A. and LUU M.B.: Current practices in biliary surgery: Do we practice what we teach? Surgical Endoscopy, 30 (8): 3345-3350, 2016. 


\section{تحقق استخلدام الرؤية الحرجة لتقنية السلامة العية

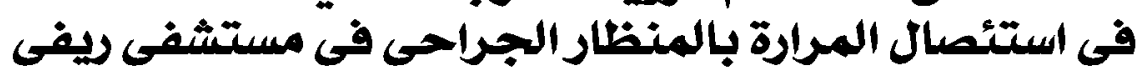

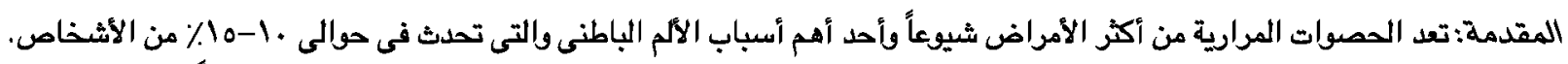

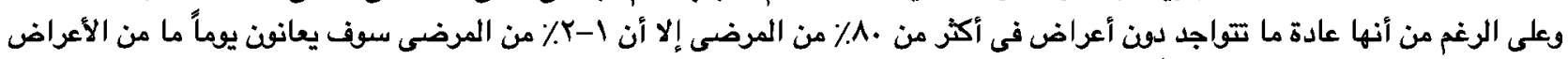

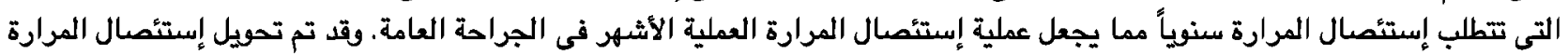

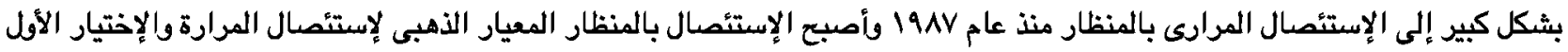

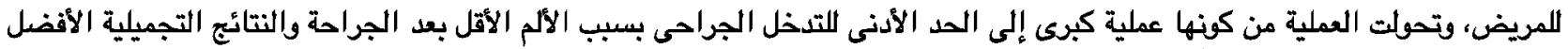

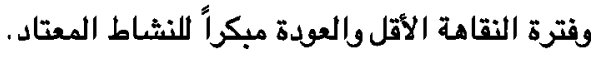

الهدف من الدراسة: الهدف من هذا العمل هو التحقق من استخدام إجراء (الرؤية الحرجة للسلامة) أثناء إستئصال المرارة بالمنظار

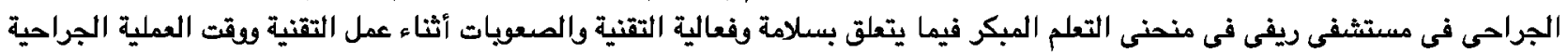
ونتائج ما بعد الجراحة.

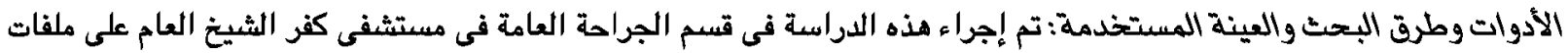

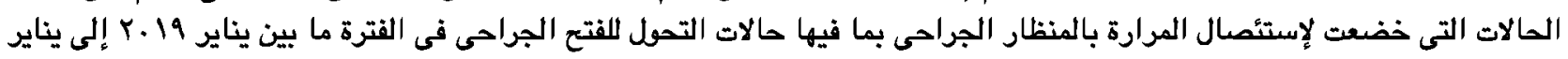

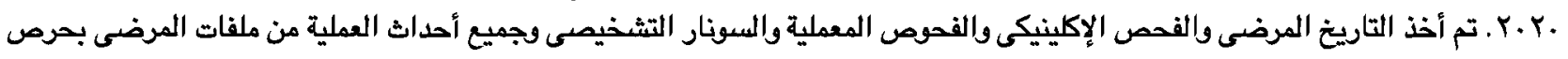

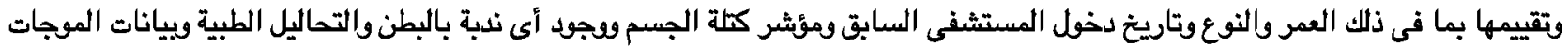
فوق الصوتية وبيانات الجراحة أثناء العملية.

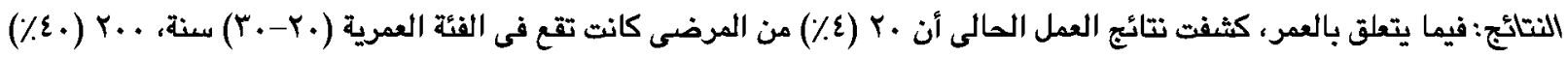

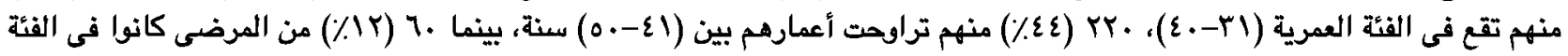

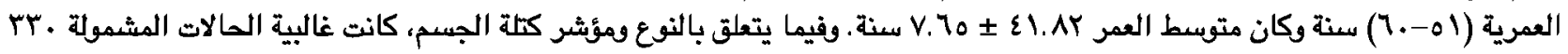

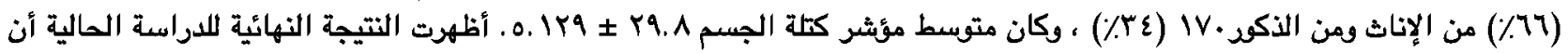

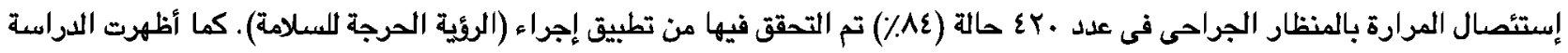

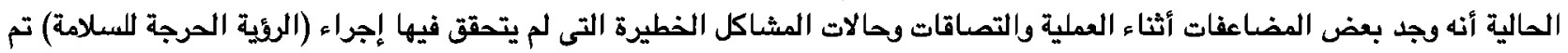

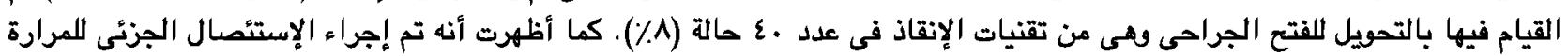

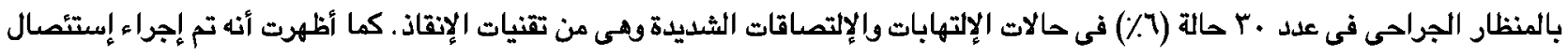

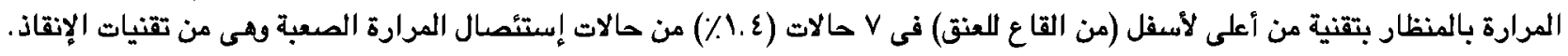

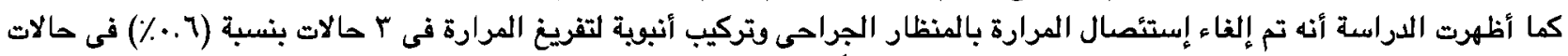

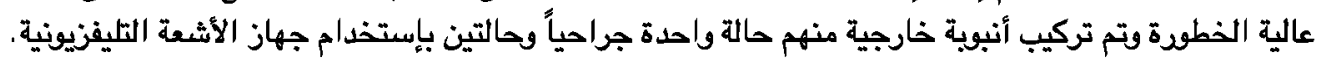

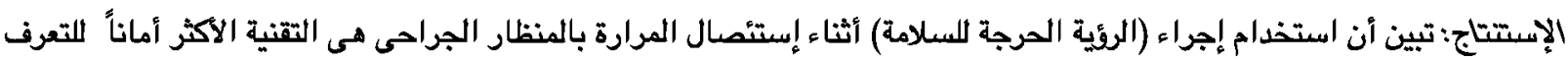

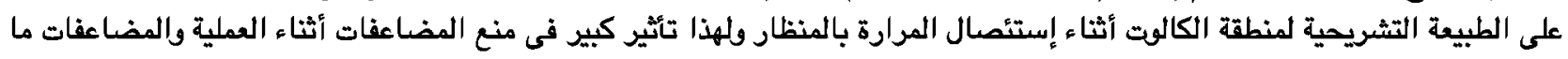

